\title{
The Prevalence and Awareness of Cardiometabolic Risk Factors in Southern Chinese Population with Coronary Artery Disease
}

\author{
Xinrui Li, ${ }^{1}$ Yuan Zhang, ${ }^{2}$ Min Wang, ${ }^{1}$ Xiaofei Lv, ${ }^{1}$ Dongfang Su, ${ }^{1}$ Zhongxia Li, \\ Ding Ding, ${ }^{1,3}$ Min Xia, ${ }^{1}$ Jian Qiu, ${ }^{2}$ Gang Hu, ${ }^{3}$ and Wenhua Ling ${ }^{1}$ \\ ${ }^{1}$ Department of Nutrition, School of Public Health, Sun Yat-sen University (Northern Campus), 74 Zhongshan Road 2, \\ Guangzhou, Guangdong 510080, China \\ ${ }^{2}$ Department of Cardiology, General Hospital of Guangzhou Military Command of People's Liberation Army, \\ Number 111 Liuhua Road, Guangzhou, Guangdong 510010, China \\ ${ }^{3}$ Chronic Disease Epidemiology Laboratory, Pennington Biomedical Research Center, Baton Rouge, LA 70808, USA
}

Correspondence should be addressed to Wenhua Ling; lingwh@mail.sysu.edu.cn

Received 24 August 2013; Accepted 15 September 2013

Academic Editors: W. S. Aronow and A. N. Makaryus

Copyright (C) 2013 Xinrui Li et al. This is an open access article distributed under the Creative Commons Attribution License, which permits unrestricted use, distribution, and reproduction in any medium, provided the original work is properly cited.

Background. Cardiometabolic risk factors significantly accelerate the progression of coronary artery disease (CAD); however, whether CAD patients in South China are aware of the prevalence of these risk factors is not clear yet. Methods. The study consisted of 2312 in-admission CAD patients from 2008 to 2011 in South China. Disease history including hypertension, dyslipidemia, and diabetes was relied on patients' self-reported records. Physical and clinical examinations were tested to assess the real prevalence of the cardiometabolic risk factors. Results. 57.9\% of CAD patients had more than 3 cardiometabolic risk factors in terms of the metabolic syndrome. The self-known and real prevalence of hypertension, diabetes, and dyslipidemia were 56.6\%, 28.3\%, and $25.1 \%$ and $91.3 \%, 40.9 \%$, and $92.0 \%$, respectively. The awareness rates were $64.4 \%, 66.3 \%$, and $28.5 \%$ for hypertension, diabetes, and dyslipidemia. The prevalence of cardiometabolic risk factors was significantly different among gender and among disease status. Conclusions. Most CAD patients in South China had more than three cardiometabolic risk factors. However, the awareness rate of cardiometabolic diseases was low, especially for dyslipidemia. Strategies of routine physical examination programs are needed for the early detection and treatment of cardiometabolic risk factors in order to prevent CAD progression and prognosis.

\section{Introduction}

Coronary artery disease (CAD), one of the major causes of morbidity and mortality worldwide [1], had become a public health problem in China during the past few decades. Recently, age-standardized CAD mortality increased in China, in contrast to the declining trends in various developed countries [2]. The overall CAD mortality rate (per 100000 individuals per year) in China was projected to rise from 95.3 in 1999 to 103.4 in 2008 [3]. In 2008, crude morbidity rate of ischemic heart disease was $12.7 \%$ among Chinese urban residents [4].

Cardiometabolic risk factors, including obesity, elevated blood pressure, triglycerides, and plasma glucose, and reduced high density lipoprotein cholesterol, are strong contributors to CAD development. More than $80 \%$ of CAD patients have at least one of these risk factors [5], but the awareness rates of these risk diseases are very low among the Chinese population. The First China National Nutrition and Health Survey showed that only $24 \%$ of hypertension patients were aware of their condition [6]. The International Collaborative Study of Cardiovascular Disease in Asia demonstrated that, among those who had a high cholesterol level, the proportion of awareness was approximately 8\% [7]. The China Heart Survey identified $87.4 \%$ undiagnosed impaired glucose regulation patients in 3513 participants hospitalized for CAD [8]. However, there are sparse data on prevalence and awareness of all the cardiometabolic risk factors in CAD population in developing countries. These risk factors affect how many CAD patients in South China and patients' awareness of these problems are not known. Determining the validated data of this question is important to guide the 
practice of clinical medicine and public health policies. In addition, physicians and patients can better understand the impact of preventing or modifying the specific risk factors on the risk of CAD progression.

The purpose of the present study is to investigate the prevalence and awareness of cardiometabolic diseases-hypertension, diabetes, and dyslipidemia - in South Chinese CAD patients. Moreover, the prevalence of metabolic syndrome is determined by physical examination and clinical tests to assess the real health status in this population.

\section{Materials and Methods}

2.1. Study Sample. Four superior specialties hospitals in Guangzhou, Guangdong, China, were chosen as study centres for the Guangdong Coronary Artery Disease Cohort. The study began in October 2008 and the recruitment period finished in December 2011. During this period, all in-admission patients who were diagnosed with CAD at the Department of Cardiology underwent eligibility screening. The inclusion criteria were (1) a history of or newly diagnosed CAD, (2) age $\geq 40$ years at baseline survey, and (3) having stayed in Guangdong province at least 5 years. The exclusion criteria were (1) age $<40$ or $>85$ years, (2) other cardiac origins (aortic valve stenosis or insufficiency, aortic dissection, acute pericarditis, rheumatic coronaritis, hypertrophic cardiomyopathy, syphilitic aortic regurgitation and cardioneurosis) and noncardiac (respiratory, gastrointestinal, or musculoskeletal) chest pain, (3) severe liver and/or kidney failure, and (4) a history of or newly diagnosed autoimmune disease or thyroid disorder. The study was approved by Sun Yat-sen University ethnic committee, and all participants or their designated relatives signed the informed consent.

2.2. Ascertainment of Coronary Artery Disease. The coronary artery disease cases were identified by using International Classification of Diseases (ICD-10) codes (I20-25). Every patient was diagnosed by cardiologists in the four hospitals according to the World Health Organization 1999/2000 guidelines $[9,10]$. Eligible diseases were defined as the occurrence of at least two of the following situations: (1) typical chest pain with the property of oppression, dullness and constriction which occurred in the middle and upper part of sternum before, (2) ST-segment deviation of $0.05 \mathrm{mV}$ or more and/or $\mathrm{T}$ wave inversion on first or histological electrocardiograph, (3) increased troponin and/or creatine kinase $\mathrm{MB}$ on initial blood tests, and/or at least one of the following situations: (1) measurable stenotic valve lesions of coronary arteries by coronary angiography and (2) history of percutaneous coronary intervention or coronary artery bypass grafting. Acute coronary syndrome (ACS) was defined as the occurrence of any of unstable angina pectoris, ST-segment elevation myocardial infarction, and non-ST-segment elevation myocardial infarction within 3 months. Severity of CAD was based on coronary angiography reports, characterized by coronary artery stenosis degree (categorized as not conduct, <50\%, 50$74.9 \%$, and $\geq 75 \%$ ) and whether triple vessel disease or not. Treatment information of CAD included percutaneous coronary intervention (PCI) and coronary artery bypass graft (CABG).

2.3. Clinical Baseline Examinations. Patients' venous blood samples were collected in the morning after fasting for 12 hours. A standardized questionnaire on general information including gender, birth date and place, address, marriage status, education level, physical activities, smoking and alcohol drinking habits, and medication history and a validated food frequency questionnaire [11] were conducted through a face-to-face interview. Smoking was defined as at least one cigarette a day and lasting more than half a year. Smoking status was classified as never, past, or current. Alcohol drinking was defined as persons who drank any type of alcoholic beverages at least once a week [12] and lasting more than six months. Alcohol drinking status was divided into never, past, or current. Medication history of hypertension, diabetes, and dyslipidemia was documented if a diagnosis had been made prior to admission and/or under relevant drugs treatment for more than 2 weeks.

Clinical measurements, including height, weight, waist circumference (WC), blood pressure, blood lipid, and fasting plasma glucose (FPG), were measured by standardized methods in each hospital. Body mass index (BMI) was calculated as weight in kilograms divided by height in meters squared. Hypertension was defined as systolic blood pressure $(\mathrm{SBP}) \geq 140 \mathrm{mmHg}$ and/or diastolic blood pressure (DBP) $\geq 90 \mathrm{mmHg}$ and/or having a hypertension history. Diabetes was defined as FPG level $\geq 7.0 \mathrm{mmol} / \mathrm{L}$ and/or having a diabetes history. Dyslipidemia was defined as any one of triglyceride (TG) $\geq 2.26 \mathrm{mmol} / \mathrm{L}$, total cholesterol (TC) $\geq 6.22 \mathrm{mmol} / \mathrm{L}$, low-density lipoprotein cholesterol (LDLc) $\geq 4.14 \mathrm{mmol} / \mathrm{L}$, and high-density lipoprotein cholesterol (HDL-c) $<1.04 \mathrm{mmol} / \mathrm{L}$ and/or having a dyslipidemia history. The metabolic syndrome was defined as the presence of at least 3 of the following 5 factors: obesity (WC $\geq 90 \mathrm{~cm}$ for male and $\geq 80 \mathrm{~cm}$ for female), elevated TG $(\geq 1.7 \mathrm{mmol} / \mathrm{L})$, reduced $\mathrm{HDL}-\mathrm{c}(<1.0 \mathrm{mmol} / \mathrm{L}$ for male and $<1.3 \mathrm{mmol} / \mathrm{L}$ for female), elevated blood pressure $(\geq 130 \mathrm{mmHg}$ for SBP and $\geq 85 \mathrm{mmHg}$ for DBP), and elevated FPG ( $\geq 5.6 \mathrm{mmol} / \mathrm{L})$ [13]. Since WC was only available in 1303 patients, $\mathrm{BMI} \geq 25 \mathrm{~kg} / \mathrm{m}^{2}$ [14] was also used to define obesity.

2.4. Statistic Analysis. Continuous data were presented as means (SDs) in total group and means (SEs) in different gender or disease status groups. Categorical data were presented as percentages. The general linear model and chisquare test were used to analyze the differences in continuous variables and in categorical variables between men and women or between subjects with acute and stable coronary artery disease. Statistical significance was considered to be $P<0.05$. All statistical analyses were performed with PASW for Windows, version 20.0 (IBM SPSS Inc, Chicago, IL, USA).

\section{Results and Discussion}

A total of 2831 eligible patients were invited to the study and informed the studying procedures in detail. After excluding 362 subjects who were unwilling to sign informed consent, 


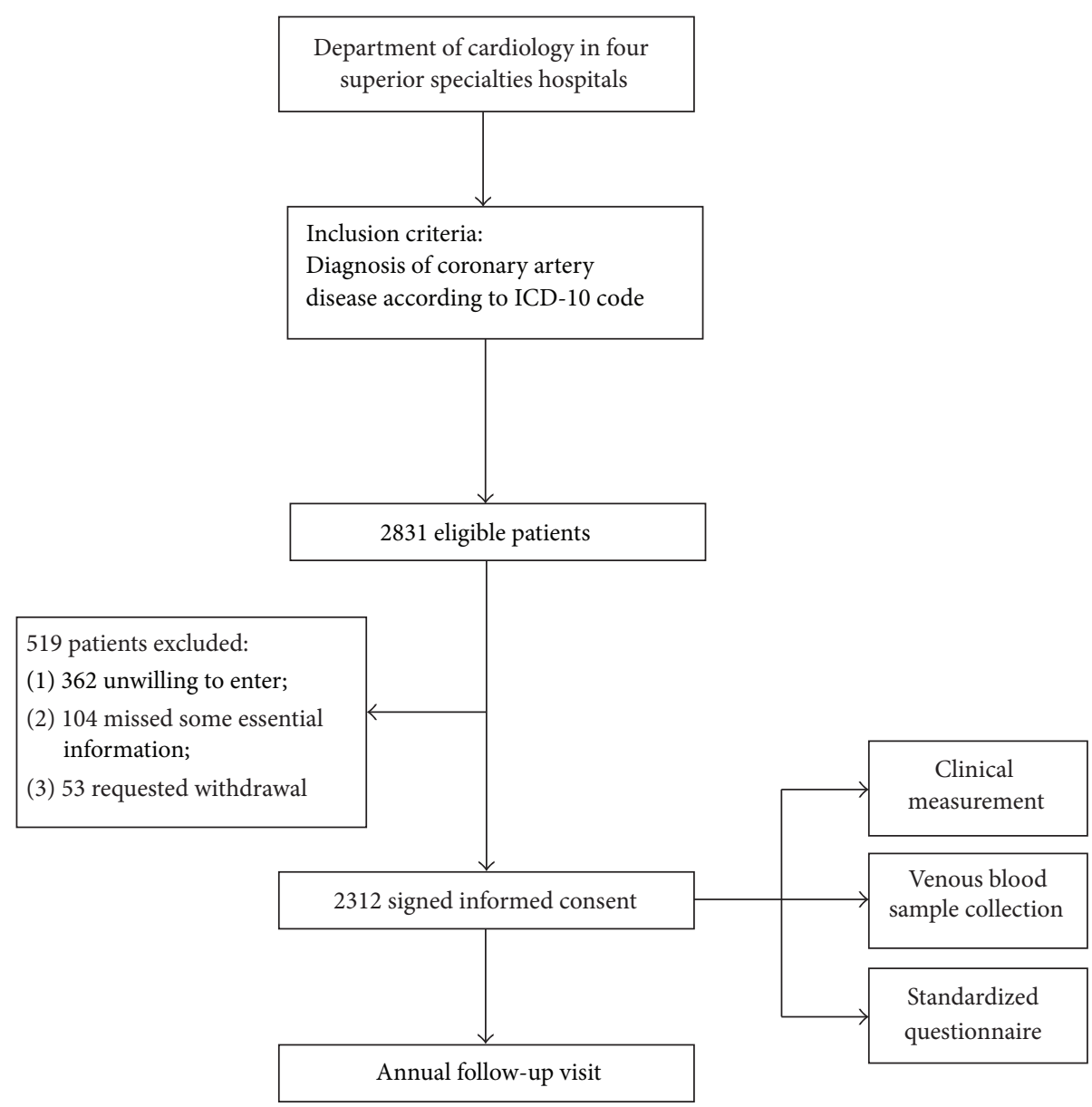

FIGURE 1: Recruitment period trail profile for Guangdong Coronary Artery Disease Cohort study.

104 missing some essential information, and 53 requesting withdrawal before discharge, 2312 subjects were included in the final analysis and would be followed in the future (Figure 1).

Males comprised of $67.1 \%$ of the population in this study (Table 1). In general, male CAD patients were younger, had a higher education level, and were more often married, current smokers, alcohol drinkers, shorter CAD duration and with more severe disease status compared with female CAD patients. Male CAD patients had significantly higher prevalence of dyslipidemia and lower prevalence of central obesity, the metabolic syndrome, elevated TG $(\geq 1.7 \mathrm{mmol} / \mathrm{L})$, and reduced HDL-c $(<1.0 \mathrm{mmol} / \mathrm{L}$ for male and $<1.3 \mathrm{mmol} / \mathrm{L}$ for female) than female CAD patients. The awareness rates of hypertension, diabetes, and dyslipidemia were all significantly higher in female patients.

About $60 \%$ of CAD patients were diagnosed with ACS at admission (Table 2). ACS patients were younger and with lower BMI and blood pressure, and they were more frequent smokers, and alcohol drinkers and with shorter CAD duration and more severe disease status than stable CAD patients. When compared with stable CAD patients, ACS patients had higher prevalence of hypertension, diabetes, dyslipidemia, elevated TG, and elevated FPG $(\geq 5.6 \mathrm{mmol} / \mathrm{L})$ but lower central obesity (WC $>85 \mathrm{~cm}$ for male and $>80 \mathrm{~cm}$ for female).
The awareness rates of hypertension and dyslipidemia were significantly lower in ACS patients than those in stable CAD patients. The difference between ACS and stable CAD in male patients was similar to the whole population, except that there were less physical activities and more metabolic syndrome in male ACS patients. However, among female patients, there were no statistical differences in cardiometabolic risk factors, diseases prevalence, and awareness between ACS and stable CAD patients.

The present study assessed the health status among 2312 inpatients with CAD in South China. The main finding was the high prevalence of cardiometabolic risk factors among patients with CAD including hypertension, diabetes, dyslipidemia, and the metabolic syndromes. More than half of the patients were aware of their hypertension or diabetes status, but few patients were aware of dyslipidemia. Compared to the male patients, female patients with CAD had higher cardiometabolic risk factors except for dyslipidemia. ACS patients had higher disease prevalence rates but lower awareness rate.

Hypertension, diabetes, and dyslipidemia are labelled as conventional risk factors for their strength of evidence supporting role in the pathogenesis of CAD. It has been indicated that about $80-90 \%$ of CAD patients have at least one of the conventional risk factors [5]. In the present study, 
TABLe 1: Patients demographic stratified by gender.

\begin{tabular}{|c|c|c|c|c|}
\hline Variable & Total $(n=2312)$ & Male $(n=1553)$ & Female $(n=759)$ & $P$ \\
\hline Age (years) & $63.7 \pm 11.4$ & $62.0 \pm 0.3$ & $67.3 \pm 0.4$ & $<0.001$ \\
\hline Body mass index $\left(\mathrm{kg} / \mathrm{m}^{2}\right)$ & $23.9 \pm 3.3$ & $23.8 \pm 0.1$ & $24.1 \pm 0.1$ & 0.129 \\
\hline Systolic blood pressure (mmHg) & $132 \pm 23$ & $131 \pm 1$ & $134 \pm 1$ & 0.001 \\
\hline Diastolic blood pressure $(\mathrm{mmHg})$ & $77 \pm 13$ & $77 \pm 1$ & $77 \pm 1$ & 0.694 \\
\hline Total cholesterol (mmol/L) & $4.63 \pm 1.12$ & $4.48 \pm 0.03$ & $4.94 \pm 0.04$ & $<0.001$ \\
\hline Low-density lipoprotein cholesterol (mmol/L) & $2.91 \pm 1.25$ & $2.84 \pm 0.03$ & $3.06 \pm 0.05$ & $<0.001$ \\
\hline High-density lipoprotein cholesterol (mmol/L) & $1.06 \pm 0.29$ & $1.01 \pm 0.01$ & $1.16 \pm 0.01$ & $<0.001$ \\
\hline Triglycerides $(\mathrm{mmol} / \mathrm{L})$ & $1.81 \pm 1.31$ & $1.76 \pm 0.03$ & $1.91 \pm 0.05$ & 0.009 \\
\hline Lysophosphatidic acid (g/L) & $0.36(0.22,0.76)$ & $0.38(0.22,0.77)$ & $0.35(0.22,0.71)$ & 0.149 \\
\hline Apolipoprotein A (g/L) & $1.10 \pm 0.28$ & $1.05 \pm 0.01$ & $1.19 \pm 0.01$ & $<0.001$ \\
\hline Apolipoprotein B (g/L) & $0.78 \pm 0.28$ & $0.76 \pm 0.01$ & $0.83 \pm 0.01$ & $<0.001$ \\
\hline Fasting glucose $(\mathrm{mmol} / \mathrm{L})$ & $6.38 \pm 2.62$ & $6.26 \pm 0.07$ & $6.63 \pm 0.10$ & 0.002 \\
\hline Uric acid (umol/L) & $376 \pm 113$ & $390 \pm 3$ & $348 \pm 4$ & $<0.001$ \\
\hline \multicolumn{5}{|l|}{ Duration of coronary artery disease (years) } \\
\hline First diagnosed patients $(n=1223)$ & - & - & - & \\
\hline History diagnosed patients $(n=1089)$ & $3.00(1.00,8.00)$ & $2.29(0.91,6.66)$ & $4.45(1.12,10.0)$ & $<0.001$ \\
\hline Marriage (\%) & 89.9 & 93.8 & 81.6 & $<0.001$ \\
\hline Years of education (\%) & & & & $<0.001$ \\
\hline$\leq 9$ & 61.4 & 57.2 & 69.6 & \\
\hline $10-12$ & 20.0 & 21.8 & 16.8 & \\
\hline$\geq 13$ & 18.6 & 21.0 & 13.6 & \\
\hline Physical activities (\%) & & & & 0.101 \\
\hline None & 35.9 & 38.1 & 31.4 & \\
\hline$\leq 30 \mathrm{~min}$ & 20.9 & 20.1 & 22.6 & \\
\hline$>30 \mathrm{~min}$ & 43.2 & 41.8 & 46.0 & \\
\hline Smoking (\%) & & & & $<0.001$ \\
\hline Never & 59.0 & 41.3 & 95.4 & \\
\hline Past & 8.0 & 10.9 & 2.0 & \\
\hline Current & 32.9 & 47.7 & 2.6 & \\
\hline Alcohol drinking (\%) & & & & $<0.001$ \\
\hline Never & 77.9 & 67.6 & 98.2 & \\
\hline Past & 6.9 & 10.2 & 0.4 & \\
\hline Current & 15.2 & 22.2 & 1.4 & \\
\hline Type of coronary artery disease (\%) & & & & $<0.001$ \\
\hline Stable status & 41.0 & 36.5 & 50.2 & \\
\hline Unstable angina pectoris & 35.1 & 30.4 & 36.1 & \\
\hline Myocardial infarction & 23.9 & 33.1 & 13.7 & \\
\hline Coronary artery stenosis degree of CAG & & & & $<0.001$ \\
\hline Not conduct & 34.9 & 28.0 & 49.0 & \\
\hline$<50 \%$ & 12.1 & 10.7 & 15.0 & \\
\hline $50-74.9 \%$ & 7.9 & 8.0 & 7.8 & \\
\hline$\geq 75 \%$ & 45.1 & 53.3 & 28.2 & \\
\hline Triple vessel disease (\%) ( $n=1181$ with CAG reports) & 51.1 & 53.5 & 43.7 & $<0.001$ \\
\hline \multicolumn{5}{|l|}{ Treatment of coronary disease (\%) } \\
\hline Percutaneous coronary intervention & 50.6 & 59.1 & 34.2 & $<0.001$ \\
\hline Coronary artery bypass graft & 2.3 & 2.8 & 1.2 & 0.018 \\
\hline \multicolumn{5}{|l|}{ History of diseases (\%) } \\
\hline Hypertension & 56.6 & 52.8 & 63.9 & $<0.001$ \\
\hline Diabetes mellitus & 28.3 & 25.7 & 33.6 & $<0.001$ \\
\hline Dyslipidemia & 25.1 & 23.8 & 27.6 & 0.046 \\
\hline
\end{tabular}


TABle 1: Continued.

\begin{tabular}{|c|c|c|c|c|}
\hline Variable & Total $(n=2312)$ & Male $(n=1553)$ & Female $(n=759)$ & $P$ \\
\hline \multicolumn{5}{|l|}{ Current prevalence of diseases (\%) } \\
\hline Hypertension ( $\geq 140 / 90 \mathrm{mmHg}$ for SBP/DBP or drug use) & 91.3 & 91.4 & 91.0 & 0.747 \\
\hline Diabetes mellitus ( $\geq 7.0 \mathrm{mmol} / \mathrm{L}$ for FPG or drug use) & 40.9 & 39.6 & 43.3 & 0.111 \\
\hline Dyslipidemia* ${ }^{*}$ & 92.0 & 93.7 & 88.9 & $<0.001$ \\
\hline \multicolumn{5}{|l|}{ Awareness rate of disease (\%) } \\
\hline Hypertension & 64.4 & 60.7 & 71.7 & $<0.001$ \\
\hline Diabetes mellitus & 66.3 & 63.3 & 71.6 & 0.011 \\
\hline Dyslipidemia & 28.5 & 26.6 & 32.7 & 0.005 \\
\hline \multicolumn{5}{|l|}{ The metabolic syndrome and its individual components (\%) } \\
\hline Defined by BMI $\geq 25 \mathrm{~kg} / \mathrm{m}^{2}$ & 57.9 & 54.3 & 65.0 & $<0.001$ \\
\hline Defined by BMI $\geq 25 \mathrm{~kg} / \mathrm{m}^{2}$ ( $n=1303$ with waist circumference) & 58.5 & 54.8 & 67.2 & $<0.001$ \\
\hline Defined by waist circumference $(n=1303)$ & 66.9 & 61.2 & 80.2 & $<0.001$ \\
\hline Obesity $\left(\mathrm{BMI} \geq 25 \mathrm{~kg} / \mathrm{m}^{2}\right)$ & 34.1 & 34.5 & 33.5 & 0.647 \\
\hline Obesity (waist circumference $>85 / 80 \mathrm{~cm}$ for male/female) & 62.5 & 53.8 & 83.2 & $<0.001$ \\
\hline Triglycerides $(\geq 1.70 \mathrm{mmol} / \mathrm{L})$ & 38.8 & 36.9 & 42.5 & 0.010 \\
\hline High-density lipoprotein cholesterol ( $<1.0 / 1.3 \mathrm{mmol} / \mathrm{L}$ for male/female) & 56.5 & 50.3 & 69.1 & $<0.001$ \\
\hline High blood pressure ( $\geq 130 / 85 \mathrm{mmHg}$ for $\mathrm{SBP} / \mathrm{DBP})$ & 93.7 & 93.7 & 93.6 & 0.922 \\
\hline Fasting plasma glucose $(\geq 5.6 \mathrm{mmol} / \mathrm{L})$ & 58.0 & 56.6 & 60.9 & 0.055 \\
\hline
\end{tabular}

Only 1303 but not all study samples measured waist circumference. CAG: coronary angiography.

${ }^{*}$ Dyslipidemia was defined as any one of triglyceride $\geq 2.26 \mathrm{mmol} / \mathrm{L}$, total cholesterol $\geq 6.22 \mathrm{mmol} / \mathrm{L}$, low-density lipoprotein cholesterol $\geq 4.14 \mathrm{mmol} / \mathrm{L}$, highdensity lipoprotein cholesterol $<1.04 \mathrm{mmol} / \mathrm{L}$, and/or using cholesterol-lowering medicines during the last 2 weeks.

we collected the data from physical examination and laboratory tests which provided more convincing information on cardiometabolic risk factors. Our investigation found that the prevalence of hypertension, diabetes, and dyslipidemia among CAD patients was $91.3 \%, 40.9 \%$, and $92.0 \%$, respectively, and the unawareness rates of hypertension, diabetes, and dyslipidemia were $35.6 \%, 33.7 \%$, and $71.5 \%$.

High blood pressure is an important public-health challenge and a great contributor to CAD morbidity and mortality. A previous study had indicated that hypertension was a greater health burden in developing countries rather than developed ones [15]. The average blood pressure level among our subjects was similar to the report of the CAD patients in the 2007-2008 China National Diabetes and Metabolic Disorders Study [16], and the prevalence of hypertension accorded with the report from the study on Reduction of Atherothrombosis for Continued Health Registry (REACH registry) [17]. Our study showed that $64.4 \%$ of hypertension patients were aware of their hypertensive condition. The awareness rate was significantly higher than that of the general population in Guangdong [18] but still a bit lower than that of America adults [19].

Both the Euro heart survey and the China heart survey $[8,20]$ demonstrated that abnormal glucose regulation was around $60 \%$ in patients with CAD. Using oral glucose tolerance tests, Euro heart survey discovered 26.9\% undiagnosed diabetes [21], and, in China heart survey, the proportion was $17.8 \%$ [8]. In concern, we identified $58.0 \%$ of patients with elevated FPG ( $\geq 5.6 \mathrm{mmol} / \mathrm{L})$ and $20.2 \%$ newly diagnosed diabetes in total. It has long been known that people with diabetes have higher mortality rates and a 2-4 times greater risk for future coronary cardiovascular disease events compared with people without type II diabetes [22, 23]. Therefore, more effective clinical treatment strategies for diabetic CAD patients are needed in our population.

The prevalence of dyslipidemia among CAD patients in Chinese multiprovince ACS study was 19.6\% [24]; however, the dyslipidemia prevalence was $92.0 \%$ in our population, including $71.5 \%$ unawareness dyslipidemia. The national data included 7 geographic districts of China where the prevalence of dyslipidemia was lower in West and Middle China. Furthermore, the national study only considered TC and LDLc to define dyslipidemia, while we defined dyslipidemia by using four biomarkers: TG, TC, LDL-c, and HDL-c. Therefore, the national average dyslipidemia prevalence was much lower than that in our study. An international randomized clinical trial [5] reported that the prevalence of dyslipidemia was $39.6 \%$ in women and $34.1 \%$ in men in the patients with CAD. But they might underestimate the true prevalence because they relied on patient self-report of risk factors. In the United States, the awareness rate of dyslipidemia was about 50.4\% during 2005-2006 [25]. Unfortunately, the awareness rate was much lower in our population, because few patients accessed to regulate physical examination. Actually, high cholesterol is the biggest contribution to CAD incidence. Early awareness and proper treatment of dyslipidemia may lower $77 \%$ of overall deaths of CAD patients [2].

The metabolic syndrome is a complex index of cardiovascular risks. The present study revealed that female patients had higher prevalence of cardiometabolic diseases than males in terms of the metabolic syndrome and its individual components. This phenomenon could not be explained by the fact that female patients were 5 years older than male patients in our study, since CAD progression was usually 


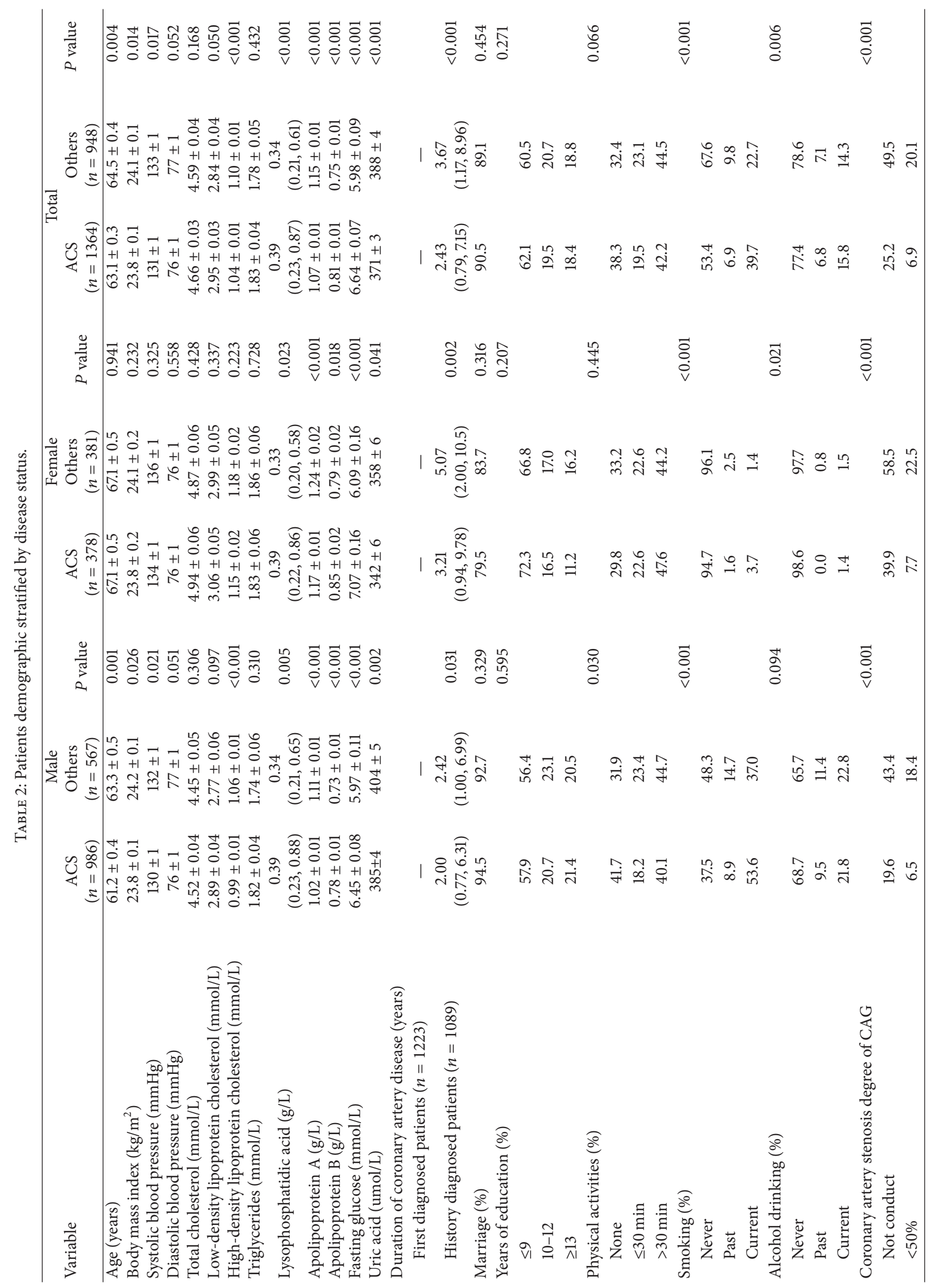




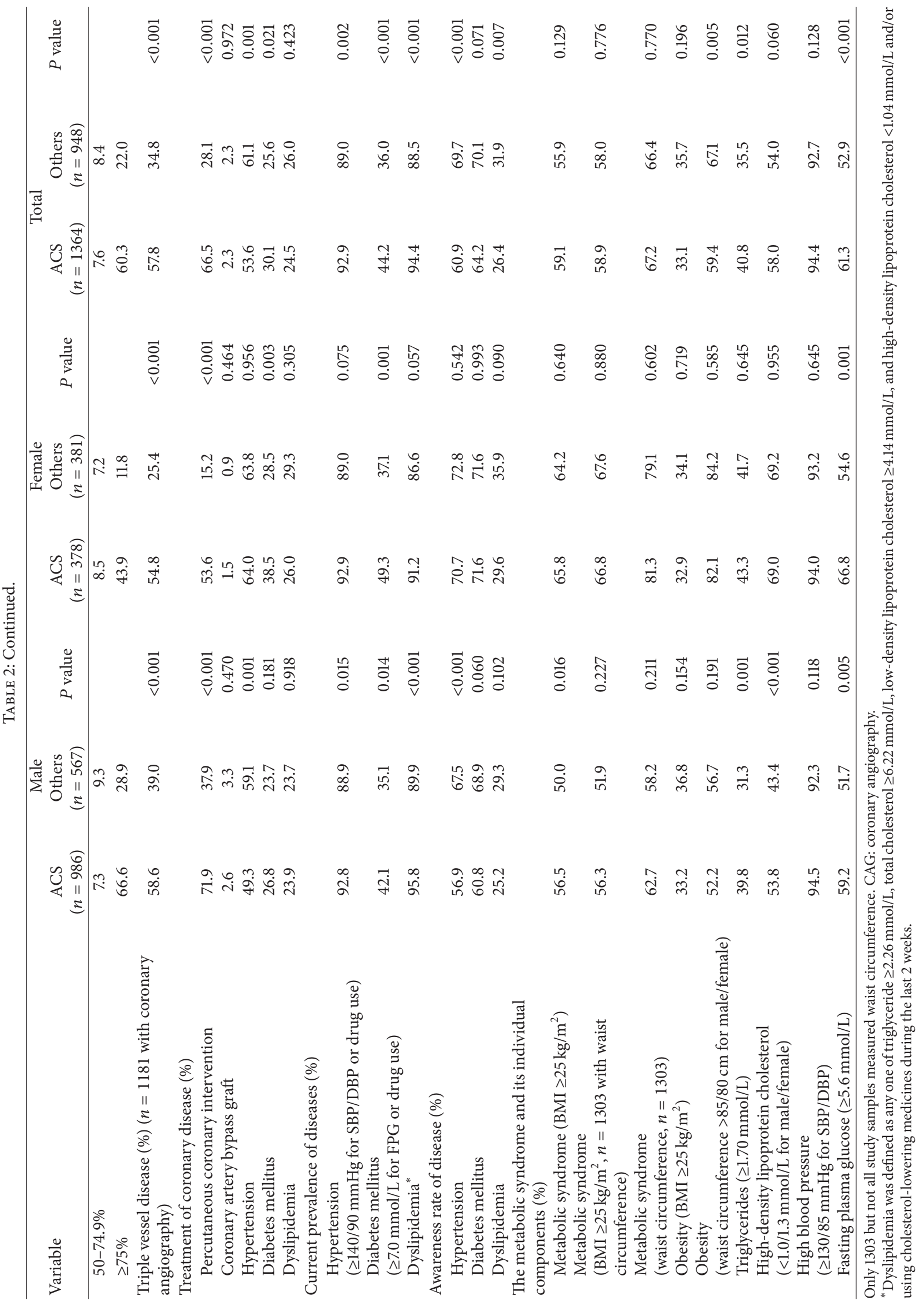


several years later in women than in men [26]. It is well known that central obesity together with hyperglycemia is a powerful risk factor in women, which may attenuate the usual protection CAD women have [27]. Furthermore, in this study, there was higher prevalence of elevated TG and reduced HDL-c in female patients though the female had lower prevalence of dyslipidemia. This might indicate a better control of lipid dysfunction in male patients. The comparison between ACS and non-ACS patients also showed that the higher the prevalence of cardiometabolic diseases, the more severe ACS events. Therefore, great attention should be paid to female patients with the metabolic syndrome.

The higher prevalence of several cardiometabolic risk factors in this study compared with other studies can be explained in several aspects. One potential reason is that the incidence of chronic disease increased rather rapidly over the past decade in China $[6,7,16,28,29]$, which would influence the proportion of cardiometabolic diseases with CAD. Another explanation may be the detrimental changes in diet and lifestyle accompanying economic development and modernization. Traditional Chinese diet rich in cereal and vegetables is dramatically changing to western-style diet. More meat and dessert intake results in weight gain, higher blood lipid, and insulin resistance, which increases CAD risk [30]. Vehicle is a substitute for bicycle and walking leading to an inactive status, which may increase CAD mortality [31]. More noticeably, the average education levels were low in this population, with $61.4 \%$ attained less than 9 years education. Abundant studies report that education levels inversely associate with diseases risk and passively relate to disease awareness and treatment compliance [32]. In the present study, female patients usually obtained much less education, and this might partly explain the higher prevalence of metabolic risk factors in female patients.

Developing countries have entered the so-called "epidemiological transition," and noncommunicable diseases mortality will account for more than $70 \%$ of all-cause deaths in 2020 [33]. The current strategies aiming at CAD prevention include mass education campaigns, diet and lifestyle interventions, and pharmacological treatment. However, these strategies are ineffective at reducing the risk factors of CAD. Most cases with unaware dyslipidemia in the present study indicate a low routine physical examination rate to the patients or general populations. Therefore, more efforts should be made in controlling complications and implementing secondary prevention for CAD patients in addition to the education on dietary pattern and lifestyle.

There were several strengths in our study, including large sample size and cardiometabolic diseases confirmation by laboratory tests. In addition, biologic samples were collected from every cohort member, which facilitated the testing of endogenous exposures and genetic factors for etiology of CAD. One limitation of our study was that some severe cases and terminally ill patients were excluded in the cohort because they could not sign the informed consent, which limited our ability to research the distinguishing features for these patients. However, investigators tried to communicate with their family members to ensure a sufficiently small refusal rate (less than 10\%). Another limitation was that WC was only available in 1303 participants for the metabolic syndrome definition, but our further study did not find any difference in baseline characteristics between patients with and without WC data.

\section{Conclusion}

Our data reported high prevalence of cardiometabolic risk factors in a South Chinese population with CAD and showed low disease awareness rates among the patients. There is a large variation in $\mathrm{CAD}$ prevalence between northern and southern Chinese [2], and our study attenuates the paucity of high-quality data about CAD in South China. Further study of this CAD population will provide a valuable opportunity to evaluate many important etiologic hypotheses for CAD which may be conducted only in this Chinese cohort.

\section{Conflict of Interests}

The authors declare that they have no conflict of interests.

\section{Acknowledgments}

The authors sincerely express their appreciation to all the medical personnel at the Department of Cardiology of the General Hospital of Guangzhou Military Command of People's Liberation Army, Zhujiang Hospital, and the First and the second Affiliated Hospital of Sun Yat-sen University for their kind assistance. They also thank all members involved in patient recruitment and data and sample collection and management in the study. This work was supported and funded by the Key Project of National Natural Science Fund (Grant no. 81130052).

\section{References}

[1] D. J. Rader and A. Daugherty, "Translating molecular discoveries into new therapies for atherosclerosis," Nature, vol. 451, no. 7181, pp. 904-913, 2008.

[2] J. Critchley, J. Liu, D. Zhao, W. Wei, and S. Capewell, "Explaining the increase in coronary heart disease mortality in Beijing between 1984 and 1999," Circulation, vol. 110, no. 10, pp. 12361244, 2004.

[3] G. Jiang, D. Wang, W. Li et al., "Coronary heart disease mortality in China: age, gender, and urban-rural gaps during epidemiological transition," Rev Panam Salud Publica, vol. 31, no. 4, pp. 317-324, 2012.

[4] C. M. o. Health, Annual Report on Health Statistics, Peking Union Medical College Press, Beijing, China, 2012.

[5] U. N. Khot, M. B. Khot, C. T. Bajzer et al., "Prevalence of conventional risk factors in patients with coronary heart disease," Journal of the American Medical Association, vol. 290, no. 7, pp. 898-904, 2003.

[6] Y. Wu, R. Huxley, L. Li et al., "Prevalence, awareness, treatment, and control of hypertension in China data from the China National Nutrition and Health Survey 2002," Circulation, vol. 118, no. 25, pp. 2679-2686, 2008.

[7] J. He, D. Gu, K. Reynolds et al., "Serum total and lipoprotein cholesterol levels and awareness, treatment, and control of hypercholesterolemia in China," Circulation, vol. 110, no. 4, pp. 405-411, 2004. 
[8] D.-Y. Hu, C.-Y. Pan, and J.-M. Yu, “The relationship between coronary artery disease and abnormal glucose regulation in China: the China Heart Survey," European Heart Journal, vol. 27, no. 21, pp. 2573-2579, 2006.

[9] R. J. Gibbons, K. Chatterjee, J. Daley et al., "ACC/AHA/ACPASIM guidelines for the management of patients with chronic stable angina: executive summary and recommendations: a report of the American College of Cardiology/American Heart Association Task Force on Practice Guidelines (Committee on Management of Patients with Chronic Stable Angina)," Circulation, vol. 99, no. 21, pp. 2829-2848, 1999.

[10] E. Braunwald, E. M. Antman, J. W. Beasley et al., "ACC/AHA guidelines for the management of patients with unstable angina and non-ST-segment elevation myocardial infarction: executive summary and recommendations: a report of the American College of Cardiology/American Heart Association task force on practice guidelines (committee on the management of patients with unstable angina)," Circulation, vol. 102, no. 10, pp. 1193-1209, 2000.

[11] B. Zhang, P. Wang, C.-G. Chen et al., "Validation of an FFQ to estimate the intake of fatty acids using erythrocyte membrane fatty acids and multiple 3d dietary records," Public Health Nutrition, vol. 13, no. 10, pp. 1546-1552, 2010.

[12] L. N. Kolonel, B. E. Henderson, J. H. Hankin et al., "A multiethnic cohort in Hawaii and Los Angeles: baseline characteristics," American Journal of Epidemiology, vol. 151, no. 4, pp. 346-357, 2000.

[13] K. G. M. M. Alberti, R. H. Eckel, S. M. Grundy et al., "Harmonizing the metabolic syndrome: a joint interim statement of the international diabetes federation task force on epidemiology and prevention; National heart, lung, and blood institute; American heart association; World heart federation; International atherosclerosis society; And international association for the study of obesity," Circulation, vol. 120, no. 16, pp. 1640-1645, 2009.

[14] S. W. Oh, S.-A. Shin, Y. H. Yun, T. Yoo, and B.-Y. Huh, "Cut-off point of BMI and obesity-related comorbidities and mortality in middle-aged Koreans," Obesity Research, vol. 12, no. 12, pp. 2031-2040, 2004.

[15] P. M. Kearney, M. Whelton, K. Reynolds, P. Muntner, P. K. Whelton, and J. He, "Global burden of hypertension: analysis of worldwide data," Lancet, vol. 365, no. 9455, pp. 217-223, 2005.

[16] Z.-J. Yang, J. Liu, J.-P. Ge, L. Chen, Z.-G. Zhao, and W.-Y. Yang, "Prevalence of cardiovascular disease risk factor in the Chinese population: the 2007-2008 China National Diabetes and Metabolic Disorders Study," European Heart Journal, vol. 33, no. 2, pp. 213-220, 2012.

[17] S. Bangalore, G. Steg, P. Deedwania et al., "beta-Blocker use and clinical outcomes in stable outpatients with and without coronary artery disease," JAMA, vol. 308, no. 13, pp. 1340-1349, 2012.

[18] B. Xu, Z. Xu, X. Xu et al., "Prevalence, awareness, treatment, and control of hypertension among residents in guangdong province, china, 2004 to 2007," Circ Cardiovasc Qual Outcomes, vol. 6, no. 2, pp. 217-222, 2013.

[19] F. Guo, D. He, W. Zhang et al., "Trends in prevalence, awareness, management, and control of hypertension among United States adults, 1999 to 2010," Journal of the American College of Cardiology, vol. 60, no. 7, pp. 599-606, 2012.

[20] E. Barrett-Connor, E.-G. V. Giardina, A. K. Gitt, U. Gudat, H. O. Steinberg, and D. Tschoepe, "Women and heart disease: the role of diabetes and hyperglycemia," Archives of Internal Medicine, vol. 164, no. 9, pp. 934-942, 2004.

[21] M. Bartnik, L. Rydén, R. Ferrari et al., "The prevalence of abnormal glucose regulation in patients with coronary artery disease across Europe: the Euro Heart Survey on diabetes and the heart," European Heart Journal, vol. 25, no. 21, pp. 1880-1890, 2004.

[22] J. Stamler, O. Vaccaro, J. D. Neaton, and D. Wentworth, "Diabetes, other risk factors, and 12-yr cardiovascular mortality for men screened in the multiple risk factor intervention trial," Diabetes Care, vol. 16, no. 2, pp. 434-444, 1993.

[23] G. Hu, P. Jousilahti, and J. Tuomilehto, "Joint effects of history of hypertension at baseline and type 2 diabetes at baseline and during follow-up on the risk of coronary heart disease," European Heart Journal, vol. 28, no. 24, pp. 3059-3066, 2007.

[24] J. Liu, D. Zhao, Q. Liu, J. Liu, J.-Y. Sun, and S. C. Smith Jr., "Prevalence, awareness, and treatment of hypercholesterolemia among inpatients with acute coronary syndrome in China," Zhonghua Xin Xue Guan Bing Za Zhi, vol. 37, no. 5, pp. 449453, 2009.

[25] E. S. Ford, C. Li, W. S. Pearson, G. Zhao, and A. H. Mokdad, "Trends in hypercholesterolemia, treatment and control among United States adults," International Journal of Cardiology, vol. 140, no. 2, pp. 226-235, 2010.

[26] I. Kardys, R. Vliegenthart, M. Oudkerk, A. Hofman, and J. C. M. Witteman, "The female advantage in cardiovascular disease: do vascular beds contribute equally?” American Journal of Epidemiology, vol. 166, no. 4, pp. 403-412, 2007.

[27] E. L. Barrett-Connor, B. A. Cohn, D. L. Wingard, and S. L. Edelstein, "Why is diabetes mellitus a stronger risk factor for fatal ischemic heart disease in women than in men? The Rancho Bernardo Study," Journal of the American Medical Association, vol. 265, no. 5, pp. 627-631, 1991.

[28] H. Wang, Q. Qiu, L.-L. Tan et al., "Prevalence and determinants of diabetes and impaired fasting glucose among urban community-dwelling adults in Guangzhou, China," Diabetes and Metabolism, vol. 35, no. 5, pp. 378-384, 2009.

[29] S. Lin, T. O. Cheng, X. Liu et al., "Impact of dysglycemia, body mass index, and waist-to-hip ratio on the prevalence of systemic hypertension in a lean Chinese population," American Journal of Cardiology, vol. 97, no. 6, pp. 839-842, 2006.

[30] A. O. Odegaard, W. P. Koh, J. M. Yuan et al., "Western-style fast food intake and cardiometabolic risk in an Eastern country," Circulation, vol. 126, no. 2, pp. 182-188, 2012.

[31] A. O. Odegaard, W.-P. Koh, M. D. Gross, J.-M. Yuan, and M. A. Pereira, "Combined lifestyle factors and cardiovascular disease mortality in chinese men and women: the singapore chinese health study," Circulation, vol. 124, no. 25, pp. 2847-2854, 2011.

[32] A. Goyal, D. L. Bhatt, P. G. Steg et al., "Attained educational level and incident atherothrombotic events in low-and middleincome compared with high-income countries," Circulation, vol. 122, no. 12, pp. 1167-1175, 2010.

[33] G. L. Khor, "Cardiovascular epidemiology in the Asia-Pacific region," Asia Pacific Journal of Clinical Nutrition, vol. 10, no. 2, pp. 76-80, 2001. 


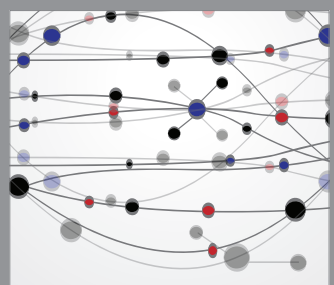

The Scientific World Journal
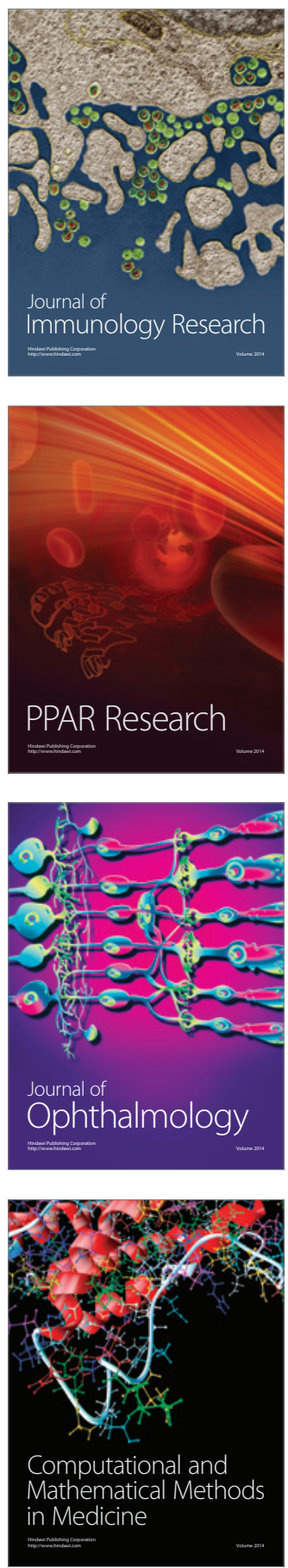

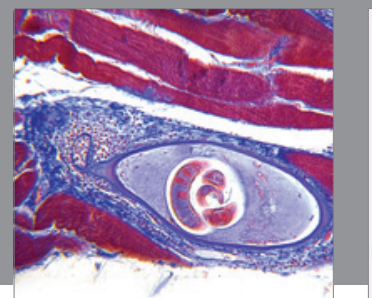

Gastroenterology

Research and Practice
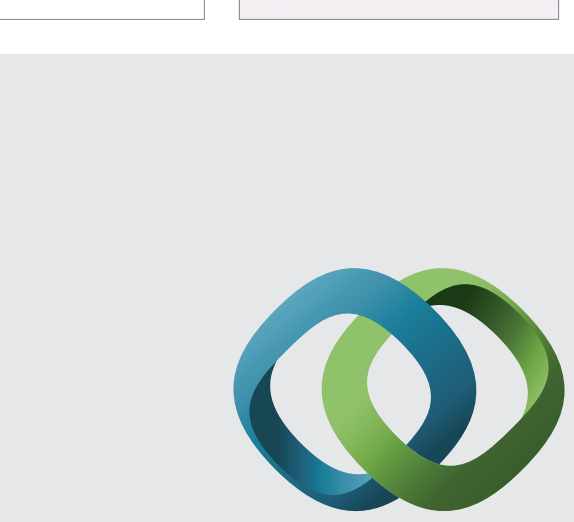

\section{Hindawi}

Submit your manuscripts at

http://www.hindawi.com
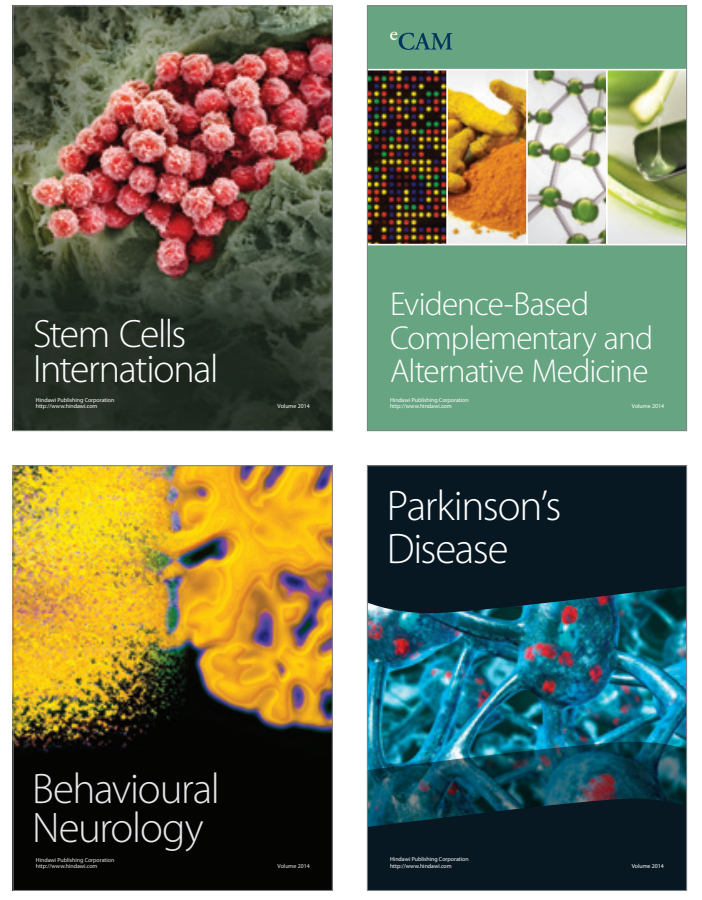
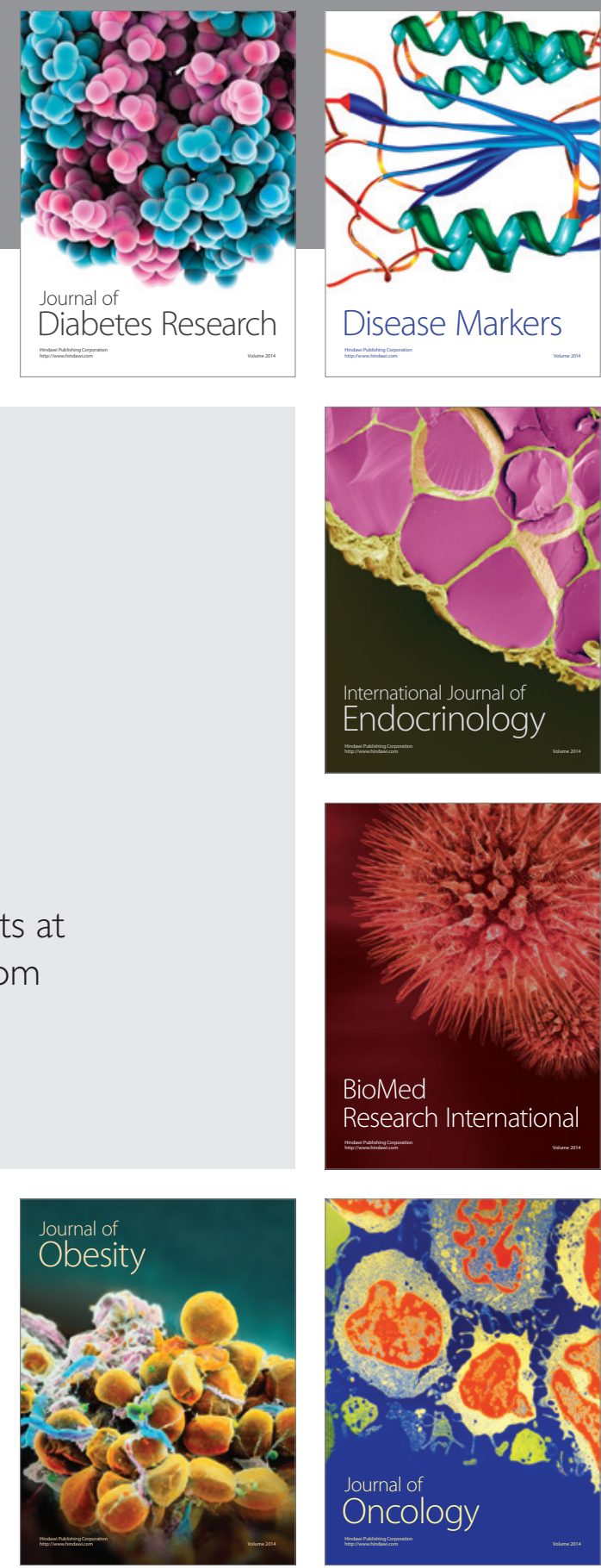

Disease Markers
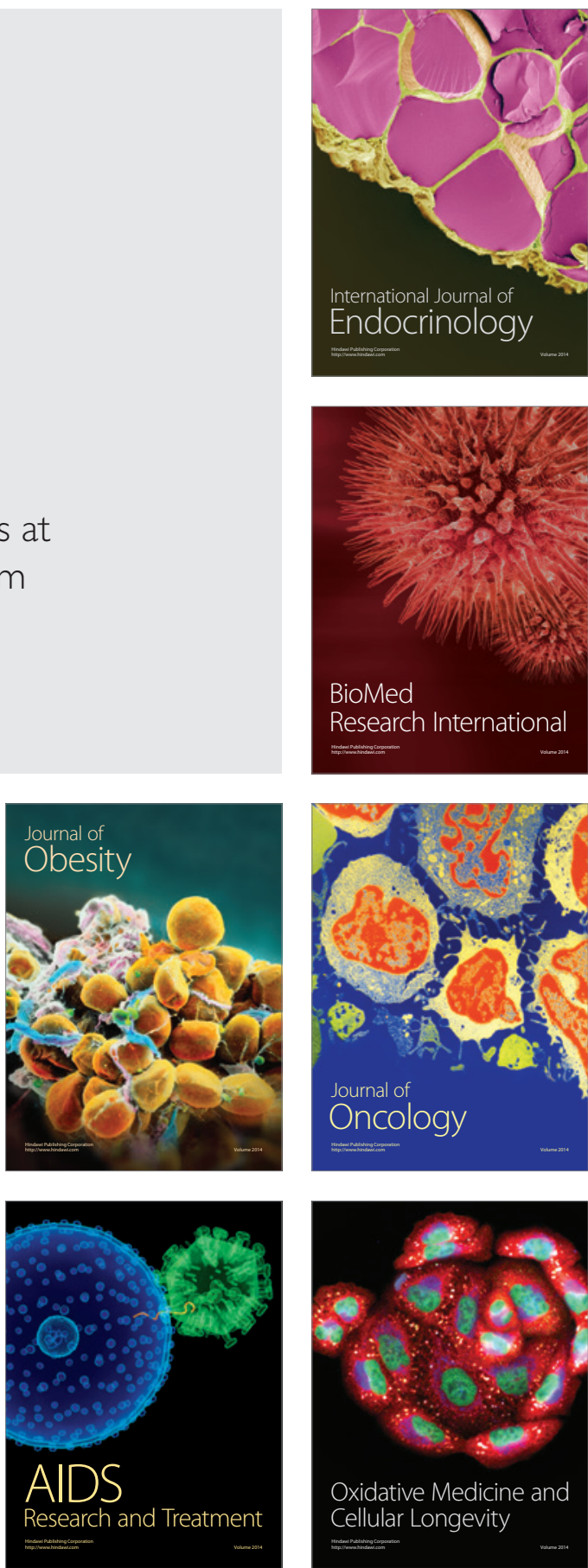